\title{
Business Negotiation as a Crucial Component of Sales
}

\author{
${ }^{1}$ Davor Perkov, ${ }^{2}$ Dinko Primorac \\ ${ }^{1}$ International University Libertas, Zagreb, Croatia \\ ${ }^{2}$ University North, Koprivnica, Croatia
}

\begin{abstract}
Negotiation is a controlled communication process that resolves the conflict of interest of two or more negotiating parties (when each party can block the achievement of the objective of the other side). The key to negotiating effectively is to know how much to offer in which moment and know where and how to draw the line of what we are prepared to accept. Negotiation theory in some segments differs from the negotiation in sales. The purpose of the paper was to point out the specific potentials, problems, dynamics and importance of negotiation as a crucial component of sales. The main hypothesis of the paper is that many companies today leave negotiation function outside of standardization in the business processes. It will be clarified what are the contents of negotiating function, how it affects development and how to acquire negotiating skills best in the sales process. The aim is to draw attention to dimensions that preparation process has when leading the course of negotiations to accomplish desired sales goals. Primary research has been conducted on the sample of fifty $(\mathrm{N}=50)$ respondents from different Croatian companies. The findings indicate that Croatian employees are not prepared quite adequately for the process of negotiation and that they are not improving their negotiation skills.
\end{abstract}

Keywords: Business negotiation, Sales process, Process of negotiation, Negotiation skills

\section{INTRODUCTION}

Negotiation is a controlled communication process that resolves the conflict of interest of two or more negotiating parties (when each party can block the achievement of the objective of the other side). If one side cannot block the achievement of the objectives of the other side, then it is not a negotiation. Negotiation is a special form of social interaction, a form of coexistence in diversity. Negotiation can even be fun if there is knowledge about what is to be done, but it could be a real source of stress if the negotiations end up as "short-sleeved". So again, proceeding in negotiation process armed with arguments, data, and even the wiles and at all costs trying to drive the result of negotiations solely to ones' will, leads in the wrong direction. Negotiations can be considered successful only when both parties are satisfied with the outcome of the negotiation. Therefore, it is clever to prepare a strategy in which there are clearly separated targets to be achieved and the details that can be "sacrificed" in favor of the opposite side in accordance with the principle of "always ready to accept a compromise."

The choice of this topic was prompted because of its importance and representation in both management theory and practice. The breadth of the topic and its development is intriguing and may be discussed from many different perspectives. The key goal is to present how CRM and loyalty programmes can influence the business result and competitiveness of two Croatian retailers. The main hypothesis of the study is that many companies today leave negotiation function outside of standardization in the business processes. Furthermore, we point out the specific potentials, problems, dynamics and importance of negotiation as an art of selling. 
This paper consists of 5 key sections. The first section briefly introduces the topic of research, main hypothesis as well as purpose, problem statement and presents the paper structure. The second section elaborates the literature review of the term and relevant business negotiation concepts. We explore best negotiation skills, strategies and practices in sale. Depending on the type of the negotiator and other factors, the negotiation strategy is created. The third section describes the research approach and design, sample and methods to test the hypothesis. The fourth section presents the research findings and the fifth section summarizes key points of the paper.

\section{LITERATURE REVIEW}

Negotiation is the principal way that people redefine an old relationship that is not working to their satisfaction or establish a new relationship where none existed before. Because negotiation is such a common problem-solving process, it is in everyone's interest to become familiar with negotiating dynamics and skills. Reduced to its essence, negotiation is a form of interpersonal communication. Together with listening skills, positive attitude and self-confidence, communication abilities are the most important prerequisites for successful negotiations. Communication is a two-way street that requires everyone involved to exchange messages. The goal is to make the own position or proposal understood by the other party, and this relies on communication ability. Negotiation is a discussion between two or more participants who are trying to find a solution to their problem. ${ }^{1}$ Michael and Sandra Rouse (2005; p.191) define negotiation as a social process of interaction and communication between people with a purpose of achieving permanent agreement based on some common interests and achieving default goals and avoiding conflicts. Although there are single negotiations between individuals or organizations, this definition highlights that negotiation is a process, a continuous assemblage of negotiations that take place during a certain period. Also, this definition highlights that agreement between two sides has to be permanent and based on common interests.

\subsection{Term and types of business negotiation}

In business, negotiation occurs between managers and staff, employers and employees, professionals and clients, within and between organizations and between agencies and the public. Negotiation is a problem-solving process in which two or more people voluntarily discuss their differences and attempt to reach a joint decision on their common concerns. This process includes constant interaction and dialogue between the parties so they can find the solution that is the best for both of them. This interaction stops to be negotiation when one party is physically, psychologically or politically incapable of saying "no" (Gosselin, 2007). According to Cohen (2002; p.3), negotiation is a process in which two or more parties work together to come to the mutually acceptable solution of one or more questions. It can relate to trade transaction, contracts or bargain of any kind. According to Čulo and Skenderović (2012), negotiation is a dialogue between two or more people or parties, intended to reach an understanding, resolve point of difference, or gain advantage in outcome of a dialogue, to produce an agreement upon courses of action, to bargain for individual or collective advantage and to craft outcomes to satisfy various interests of two parties involved in negotiation process. Negotiation is a process where each party involved in negotiation tries to gain an advantage for themselves by the end of the process. Therefore, negotiation is intended to aim at compromise. Negotiations have particular importance in business. Some people say that "the business life is a permanent negotiation with other people who are defending their own interests". In business environment, negotiation is usually connected with 2 areas: the first one is commercial one, actually buying and selling and the other one are mutual relationships in an organization.

Also, there are many other areas where it is useful to own negotiation skills: negotiation related to time, conditions and way of delivery, break length and time for the employees, schedule for meetings, etc. (Baines, 1994). Negotiations can be divided in different types, depending on goals, time, mutual relationships of included parties and potential conflict. Based on result, negotiations can be divided on integrative and distributive, while Michael and Sandra Rouse (2005) add another type of negotiation, destructive one (Figure 1 ).

'http://www.beyondintractability.org/essay/negotiation (access: Sep 8th 2015) 


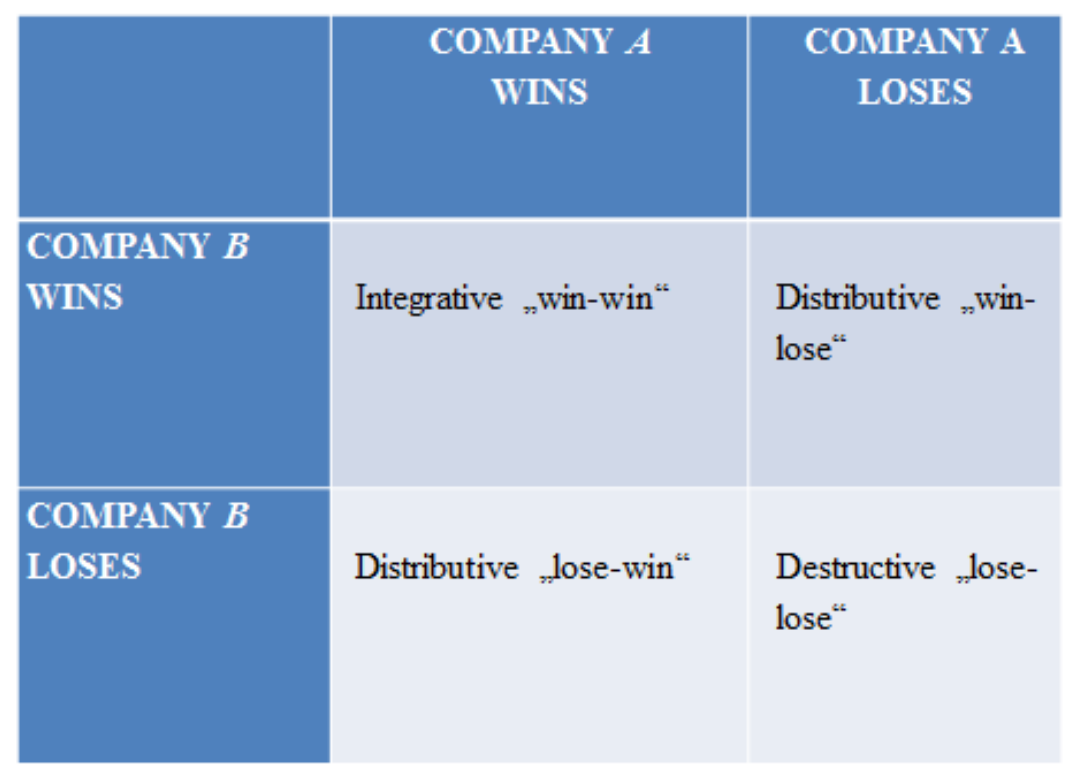

Figure 1: Negotiations based on result

Integrative negotiations finish when both parties get what they want. During distributive negotiations both parties seek to win no matter the win for other party and usually the win of first party is the loss for another one. Only distributive negotiation focuses on interests of both parties, and it should be applied if the ability of negotiations is intended to be used as a source of competitive advantage. In fact, other ways of negotiation do not depart from such a broad front of objectives, or the funds, and they are therefore called strategies of reduced negotiation (Tudor, 1992). Destructive negotiations are processes in which both parties seek to win even though there is a possibility to lose (even though they already won formally). Sometimes individuals or organizations want to hurt another party so they can prove their opinion and so they can win at any cost. However, at the end of that process, they tend to become losers.

\subsection{Preparations and sales negotiation outcomes}

According to Lisanin (2004), first and very important phase of each sales negotiation process are the preparation and planning. Usually, this stage provides from 70 to $90 \%$ success during the negotiations. The main task of this phase is to identify and study the available sources of information, and based on them, examine and identify needs, wishes and opportunities important to another negotiation party. At this stage, it should be taken into account not only the organizational needs but also individual characteristics and needs of those who will participate in the sales negotiations.

It should not be forgotten that both sides enter into negotiations as persons and individuals with their own needs. Here lie the abilities to find a win-win solution that would maximally satisfy both sides, regardless of entering into negotiations because of the disagreement existence or conflict of interest. The diversity of the real needs and views regarding the priorities of their satisfaction is just what enables the win-win outcomes in the most difficult circumstances, unless both sides try.

Before attending the negotiations it should be established what should be disclosed or provided for what we need and expect from the negotiations. In addition to the established base, maximum, minimum and target positions, there must be anticipation for the thing that might be the key or problematic in the way of an agreement. The second phase of the negotiations is the negotiating session itself or meeting in which there are attempts to reach an agreement. 


\title{
Davor Perkov, Dinko Primorac \\ Business Negotiation as a Crucial Component of Sales
}

At the very beginning, it is necessary to do everything possible to reduce tensions and to express the intent for a successful outcome for all parties. Firstly, negotiating sessions are essentially composed by the harmonization and ratification of the agenda and presentation of items that will be discussed. That should create the base for negotiation process, revealing the real needs and starting positions of each party.

The next steps are the concrete proposals and discussion about arguments, possible solutions, concessions and items that could be possible to exchange or that could be ultimately exchanged. Two parties express their different points of view. Negotiators should always be sure that for the concessions they make, they should always get that (or approximately that) value in return. Otherwise, it may happen that the negotiation outcome is worse than it was before. In the win-win approach to negotiations, preparation will include many seemingly minor issues such as: determining the place of negotiations, determining an equal number of team members and care about the environment and schedule of negotiators. Also, sales negotiator must make the basic concepts based on following: ${ }^{2}$

\author{
$\checkmark \quad$ Alternative negotiations \\ $\checkmark$ Minimal limit for accomplishing agreement \\ $\checkmark$ How flexible will he or she be and which compromises is he or she willing to make? \\ $\checkmark$ BATNA (Best Alternative To a Negotiated Agreement) \\ $\checkmark$ The lowest/the highest acceptable price \\ $\checkmark$ ZOPA (Zone of Possible Agreement)
}

All of that should lead to creating a supportive and pleasant environment for everyone involved. Winwin is a whole philosophy of human interaction because both sides win. Agreements or solutions are mutually beneficial and satisfying (Cohen, 2002). From the other hand, a win-lose approach usually takes preparation in thinking and arranging various traps, ways of expressing power and many manipulative techniques which will help achieve the pressure and dominance over the other side. Such approach does not contribute to building confidence and nurturing relationships in the long run. If the opposing party still insists on the use of pressure, unverified information and weak arguments, such tactics can be publicly discredited, but it is always necessary to keep personal integrity and to provide a new chance to turn the negotiations into a collaborative environment. Proper preparation in advance and a clear understanding of the minimum goals that we want to achieve with negotiations combined with the awareness of the best alternative to the supposed agreement will help not letting possible large pressures in negotiations to end in a way that later regret will follow. Sometimes it's better to get out of the sales negotiations in time, rather than accept extremely unfavorable solutions that perhaps are even the long-term binding.

\subsection{Strategies and Best Practices of Negotiations in Sales}

Understanding the other party's interests and tactics is integral to good negotiating. Choosing a strategy that best responds to their interests and tactics will help you achieve the best outcome. Lewicki et al. (2009) suggest that goals have to be the path of the negotiation strategy. Negotiators must foresee which goals they want to achieve in negotiations and they must focus on how to do that. Being able to negotiate well, impacts many key factors in careers. Negotiation is done for jobs and salaries, for promotions and resources, with clients and in sales. According to Grant (2014) the best practices of negotiations are:

\section{Sharing information}

Negotiation is often approached to with guard and not showing all cards. Yet, while some believe this is a smart approach, it has a negative impact on outcomes and inhibits trust. People tend to be matching and to follow the norm of reciprocity, responding in kind to how we treat them.

\footnotetext{
2 http://www.colorado.edu/conflict/peace/example/fish7513.htm (access: Nov 20th 2015) 
If we want to be trusted, we must first offer it. Studies have shown that revealing some information, even when it is unrelated to the negotiation, increases the outcome. There is no need to put all cards on the table at the outset. Simply putting something of one's out there - hobbies, personal concerns, or hopes - can set a positive tone that's conducive to gaining agreement.

\section{Ranking in order priorities}

Typically, when there is negotiation, it is known what the key issues are, and they are sequenced. For example, when trying to close a new client, it might be said that the price is most important, and if no one agrees, there's no use to continue. Grant's research shows that we are able to achieve better outcomes by ranking and leaving all the issues on the table and being transparent about it. In that way both parties can compare their rankings and determine what the full sets of options really are.

\section{Go in knowing targets price and walk away terms}

Walk away price (or terms) is reservation price. The highest price that buyer is willing to accept from a seller before they are no longer interested in purchasing. Target price is the goal we are hoping for. Often we go into negotiations with one or another - or letting the partner start the bidding. This puts entire team at a huge disadvantage. It is critical to do the research ahead of time here. Research is to be based on firm data, as not only will it provide more confidence and power to the team, but it also reduces the chance of throwing something crazy out there. By knowing team's own range, it will help make better decisions at the moment, and be clear about the limits.

\section{Make the first offer}

This is one piece of advice that clearly defies conventional wisdom. In negotiations, information is often equated with power. It is best to extract as much as possible from the other person before tipping our own hand. Fixed-pie negotiations assume there is a limited amount of benefit to go around. Take it or leave it is a fairly uncreative thing to say in a negotiation. ${ }^{3}$ People who make first offer get better terms that are closer to their target price. The reason is the psychological principle of anchoring. Whatever the first number is on the table, both parties begin to work around it. It sets the stage. Often we are reluctant to go first because we may be way off, and disengage the other party. Higher prices make the buyer focus on the positives, while lower ones invite focus on the downsides. In other words, we find data that supports this anchor. Consider real estate: a high-priced home makes us look at all the desirable qualities, while a below-market offering brings up a bad location or needed repairs. Ideally the best first offer is one that's just outside the reservation price.

\section{Don't counter too low}

If the first offer cannot be made, then the team needs to protect themselves against the anchoring effect. Caution: most people go too low, too quickly. The counter should be based on the same information the team would have used if they would make the first offer. Re-anchoring is also to be considered. Letting the other person know that their offer is way off, and go back in with a new reset. It also may be helpful to call out what is observed to redirect the conversation.

\section{Counter offers make both parties more satisfied}

Every buyer wants to feel that they got a good deal; every seller wants to feel as if they drove a hard bargain. Parties are most satisfied on both fronts if there was some back and forth. It is advised that the first offer should not be taken, even if it meets desired needs. By going back and asking for concessions it can be ensured that the best deal is done, and it will increase teams' satisfaction as well. More satisfied partners are more likely to work harder and be more committed to the end result, which is the ideal outcome from the start.

3 http://www.forbes.com/sites/larrymyler/2015/06/01/four-ways-to-win-any-negotiation/ (access: Nov 20th 2015) 
Understanding the other party's interests and tactics is integral to good negotiating. Choosing a strategy that best responds to their interests and tactics will help achieve the best outcome. Strategy is the general plan of achieving goals. When the negotiators state their goals, they move on to the next element of the course: choice and development of the strategy. Some of the different strategies for negotiation include: ${ }^{4}$

- Problem solving: both parties committing to examining and discussing issues closely when entering into long-term agreements that warrant scrutiny.

- Contending: persuading your negotiating party to concede to your outcome if you're bargaining in one-off negotiations or over major 'wins'.

- Yielding: conceding a point that is not vital to you but is important to the other party; valuable in ongoing negotiations.

- Compromising; both parties forgoing their ideal outcomes, settling for an outcome that is moderately satisfactory to each participant.

- Inaction: buying time to think about the proposal, gather more information or decide your next tactics.

Chosen strategy will depend on with who the negotiations are conducted and the type of relationship towards them. For example, what level of cooperation and common interest exists between the two, and how will each party behave during the negotiation? It will also depend on what they are negotiating and the time frame. The ability to defend one's point of view and the ability to convince the opponent in one's own point are often key elements of success. Leaving aside the emotions and dishonest rhetorical questions, the negotiator is always armed with well-built line of argument. ${ }^{5}$

\section{METHODOLOGY}

This section describes the research approach and design, sample of respondents and instruments. The main working hypothesis of this paper was that many companies leave the negotiating function outside of standardization in the business processes. That speaks of the many mistakes companies are confronted with when designing future goals and sales objectives. In this paper the subject of research is negotiating function as one of the key sales capabilities to which special attention, importance and appropriate access must be given.

\subsection{Sample Analysis}

We used secondary and primary data sources. Secondary sources included domestic and foreign scientific and professional literature, as well as relevant online databases. The research of literature was conducted by desk research method. Primary information sources have been obtained through empirical research of sales negotiation processes in different Croatian organizations. Using an online survey, 50 individual respondents were included (Figure 2).

In the section "other", two respondents were employed in culture and two in servicing. In the branches of education, transport, science and high education, traffic, precise mechanics and electronics, vehicle servicing, agricultural production, honey production, maintenance of motor vehicles, geodetic services and informatics, bookkeeping and business counseling, there was only one respondent employed.

\footnotetext{
${ }^{4}$ https://www.business.qld.gov.au/business/running/managing-business-relationships/negotiatingsuccessfully/negotiating-strategies (access: Nov 20th 2015)

${ }^{5}$ Authors translation from: Nepryahin Nikita (2010). Ybejday $i$ pobejday. Secreti efektivnoy argymentacii. Moskva: Alpina Pablisherz. P. 132
} 
Davor Perkov, Dinko Primorac

Business Negotiation as a Crucial Component of Sales

\begin{tabular}{|l|r|l|r|}
\hline \multicolumn{1}{|c|}{ VARIABLE } & $\begin{array}{c}\text { Structure } \\
(\%)\end{array}$ & \multicolumn{1}{|c|}{ VARIABLE } & $\begin{array}{c}\text { Structure } \\
(\%)\end{array}$ \\
\hline Age & 8 & Gender & 60 \\
\hline $20-30$ & 42 & Female & 40 \\
\hline $31-40$ & 50 & & $\begin{array}{l}\text { Number of employees } \\
\text { in an organization }\end{array}$ \\
\hline 41 and more & 18 & $1-50$ & 66 \\
\hline Branch & 4 & $51-100$ & 48 \\
\hline Retail & 4 & 101 and more & \\
\hline Construction & 6 & & \\
\hline Tourism & 6 & & \\
\hline Industrial production & 4 & & \\
\hline Finance & 6 & & \\
\hline Catering & 8 & & \\
\hline Local government & 8 & & \\
\hline Forestry & 36 & & \\
\hline Undeclared & $\mathbf{2}$ & \\
\hline Other & & & \\
\hline
\end{tabular}

Figure 2: Sample analysis

\subsection{Questionnaire Data Collection}

For creating the questionnaire Google Forms on Google Drive was used. The primary research was conducted from $9^{\text {th }}$ to $18^{\text {th }}$ of November, 2015. Fifty respondents could not be younger than 20 years, because it is assumed that negotiation duty can be led by people that are employed and have more experience. The questionnaire summarized 11 questions. Most of the questions were closed-type, while some questions were open-type so that respondents could offer an additional answer, in case it is not offered.

Key methods used in the conducted research include logical methods. Particularly the methods of analysis, synthesis, deduction and comparison were applied from this group of methods. Mathematical and statistical methods were also applied in this paper.

\section{ANALYSIS OF RESULTS}

This section was designed to present the study results and evaluate findings in a way to test the stated hypothesis. Respondents answered 11 questions about personal data, attendance of negotiation education, frequency of coordination with the team before the negotiation process, outcomes of negotiations and finally, about attributes (perks) good negotiator should have. Most of the questions were closed-type. Respondents received the questionnaire in form of Google Forms through e-mail. The results of survey are shown in Figure 3 and Figure 4.

The responses indicate that $8 \%$ of the respondents often attend seminars, courses or some other types of education to improve negotiation skills (Figure 3 ). $38 \%$ of them attend these programmes few times a year, while $36 \%$ do that only once a year. $18 \%$ of respondents are not attending any type of education at all (variable 1 ).

Not attending training and not investing in improving negotiating skills can significantly affect the ability of negotiators. There is a possibility that due to financial constraints people are unable to pay a course or training which requires money. On the other hand, there are many seminars, internet sources and additional literature which are either financially acceptable or completely free.

It all depends on the willingness and commitment of the people in the negotiation process and whether they want to expose themselves more in that direction or not. 


\begin{tabular}{|c|c|}
\hline Variable & Structure (\%) \\
\hline $\begin{array}{l}\text { 1. Number of attended educations in order to improve negotiation skills: } \\
\text { - Often } \\
\text { - } \text { Oncw times in year } \\
\text { - Not attending at all }\end{array}$ & $\begin{array}{r}8 \\
38 \\
36 \\
18\end{array}$ \\
\hline $\begin{array}{l}\text { 2. Number of conducted team coordination and advising before the } \\
\text { negotiations: } \\
\text { - Never } \\
\text { - Once before negotiations } \\
\text { - } 2-5 \text { times before negotiations } \\
\text { - } 6 \text { and more times before negotiations }\end{array}$ & $\begin{array}{r}18 \\
39 \\
39 \\
4\end{array}$ \\
\hline 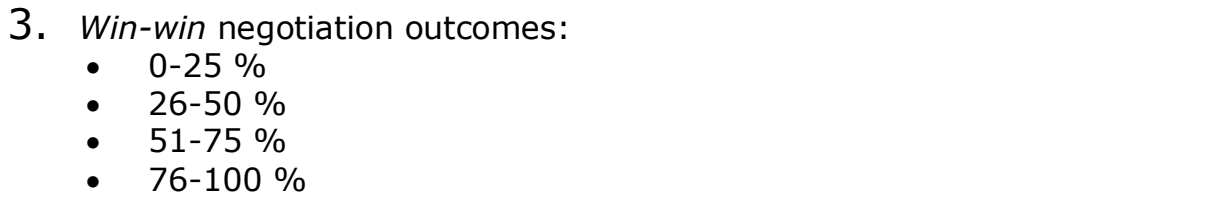 & $\begin{array}{l}14 \\
18 \\
30 \\
38\end{array}$ \\
\hline $\begin{array}{l}\text { 4. Win-lose outcomes: } \\
\begin{array}{l}\text { - } \quad 0-25 \% \\
\text { - } 26-50 \% \\
\text { - } 51-75 \% \\
\text { - } 76-100 \%\end{array}\end{array}$ & $\begin{array}{r}50 \\
32 \\
16 \\
2\end{array}$ \\
\hline 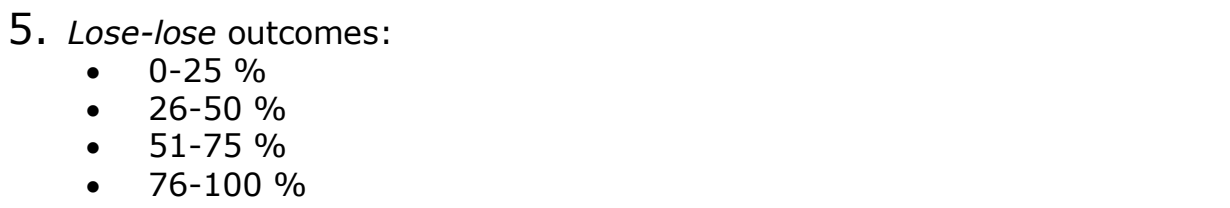 & $\begin{array}{r}74 \\
22 \\
4 \\
0\end{array}$ \\
\hline $\begin{array}{l}\text { 6. Lose-win outcomes: } \\
\begin{aligned}- & 0-25 \% \\
- & 26-50 \% \\
& -51-75 \% \\
- & 76-100 \%\end{aligned}\end{array}$ & $\begin{array}{r}82 \\
14 \\
4 \\
0\end{array}$ \\
\hline
\end{tabular}

Figure 3: Importance and number of attended education, advising before the negotiations and sales negotiation outcomes $(\mathrm{N}=50)$

Under variable 2 we can see that 57\% participants meet with their team in order to coordinate and harmonize only once or never before the negotiations. 43\% of them meet from 2 to 6 times before negotiations. It is evident that they believe that the preparation, coordination and harmonization with the team prior to the negotiations have a big importance. These results indicate a lack of awareness of employees about the importance of preparation for the sales negotiations. Coordination and harmonization with the team are always a smart move. No matter how many years people are working together, how long they knew the others and how many people are used to the interpersonal relationship between them, it can never be known to whom one will speak at the negotiating table. Information is the most important resource of today's sales and it is always advisable for the team to be engaged in the coordination prior to negotiations in order to prepare better for the negotiation process.

Whereas the third variety of win-win outcomes is present in more than $76 \%$ cases, for the majority of respondents $(82 \%)$, win-lose outcome has up to $50 \%$ representation in their sales negotiations (variable 4). It can be concluded that the vast majority of negotiations, for the respondents in the questionnaire, are ending with victory, but also the victory of the other side. It speaks that in most cases compromise is achieved, and that no one's needs, demands or proposals are ignored.

According to the questionnaire of all employees, who attend negotiation training 6 or more times a year, $76 \%$ to $100 \%$ of negotiations are ending win-win outcome. Research has shown that, if there is know-how, negotiation can have a positive outcome for both sides. Variable number 5 shows that 37 (74\%) respondents believe that up to $25 \%$ (or less) of their overall sales negotiations ends with a lose-lose situation. $22 \%$ of respondents said that that percentage varies from $26 \%$ to $50 \%$. 


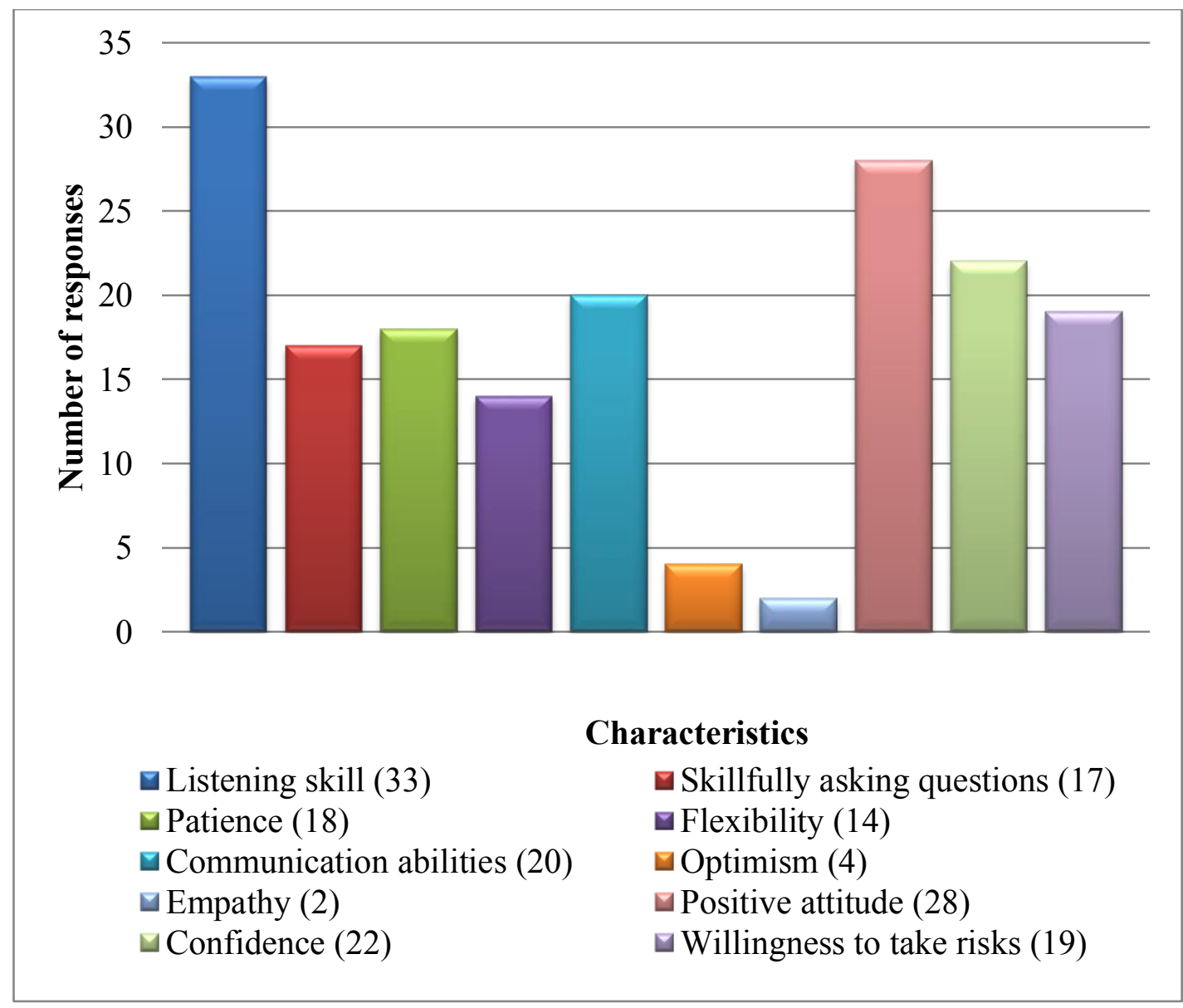

Figure 4: Most important characteristics of a good sales negotiator $(N=177)$

The research indicates that an extremely small number of negotiations ends with a lose-lose outcome. It points to the fact that they know what they are doing and know how to reach a compromise and the best solution for both sides. Variable number 6 shows share of respondents by lose-win end in negotiations. It is shown that majority of 41 respondents (82\%) finished their negotiations with losewin outcome in less of $25 \%$ cases. $7(14 \%)$ respondents said that that percentage varies from $26 \%$ to $50 \%$. No respondents said that 76 or more their negotiations end up in a lose-lose neither lose-win situations. These results can be equated with the results from the previous paragraph. For $48(96 \%)$ of respondents negotiations rarely end with a lose - win outcome, and for only four of them (4\%) the outcomes of lose-win are more often their negotiations.

In the last part of the research, the respondents expressed their opinions on open question: What qualities (characteristics) make a good negotiator? Due to total of 177 responses, the most important characteristics are (Figure 4$)$ : listening skills (19\%), positive attitude $(16 \%)$, self-confidence (13\%) and communication abilities (12\%).

Willingness to take risks was cited in $11 \%$ questionnaires, patience in $10 \%$, skilfully asking questions in $9 \%$ and flexibility in $7 \%$. The characteristics that have received the least of the respondents' votes were optimism and empathy. The research indicates that today it is very important to listen and not just blindly following thoughts and actions, but also paying attention to the other side. If you listen carefully, a lot can be heard. If a lot is heard, the easier it can be to understand the situation. If the situation is easier to understand, it is easier to come up with a positive outcome. 


\section{CONCLUSION}

Negotiation theory in some segments differs from the negotiation in sales. In this paper negotiation process was shown as a crucial component of sales. The goal was to draw attention to dimensions that preparation process has when leading the course of negotiations to accomplish desired sales goals. The main hypothesis was that many companies today leave negotiation function outside of standardization in the business processes.

From our primary online research conducted in year 2015 among fifty $(\mathrm{N}=50)$ domestic sales negotiators, it follows that Croatian employees are not prepared quite adequately for the process of negotiation and that they are not improving their negotiation skills. Majority of negotiations have a win-win or win-lose outcome and minority of negotiations have a lose-lose or a lose-win outcome. Due to our research, listening skills, positive attitude, self-confidence and communication abilities are the most important characteristics of good sales negotiator.

Considering the limitations which derive from inadequate number of respondents, the results of this research need to be taken with a grain of salt, i.e. they should not serve as the basis for making general conclusions about sales negotiations in Croatian organizations. However, the results are quite indicative and statistically reliable for a deeper understanding of the importance of negotiations skill in modern business. In conclusion, this research might deserve an expansion with a larger sample in the future in order to make strong and general statements about these issues in Croatian economy.

\section{REFERENCES}

- Baines, A. (1994). Negotiate to Win. Work Study: Volume 43, CrossRef

- Cohen, S. (2002). Negotiating Skills for Managers. Wisconsin: McGRaw-Hill, CrossRef, CrossRef, $\underline{\text { CrossRef }}$

- Culo, K., Skenderovic, V. (2012). Communication in the Process of Negotiation. Informatologija. Vol. 45, prosinac 2012, No. 4, str. 323-327.

- Gosselin, T. (2007). Practical Negotiating: Tools, Tactics and Techniques. New Jersey: John Wiley \& Sons Inc.

- Grant, A. (2014). Give and Take: Why Helping Others Drives Our Success. Penguin.

- http://www.beyondintractability.org/essay/negotiation (access: Sep 8th 2015)

- http://www.colorado.edu/conflict/peace/problem/intpos-p.htm (access: Nov 20th 2015)

- http://www.forbes.com/sites/larrymyler/2015/06/01/four-ways-to-win-any-negotiation/ (access: Nov 20th 2015)

- https://www.business.qld.gov.au/business/running/managing-businessrelationships/negotiating-successfully/negotiating-strategies (access: Nov 20th 2015)

- Lewicki, R., Saunders, M. D., Barry B. (2006). Pregovaranje. Zagreb: Mate.

- Rouse, M. J., Rouse, S. (2005). Poslovne komunikacije. Zagreb: Masmedia.

- Tomasevic Lisanin, M. (2004). Pregovaranje kao poslovni proces koji dodaje vrijednost. Zbornik Ekonomskog fakulteta u Zagrebu. Godina 2, broj 1. Str. 152. (access: Nov 15th 2015 from: hrcak.srce.hr/file/41454)

- Tudor, G. (1992). Kompletan pregovaracc-umijece poslovnog pregovaranja. Zagreb: MEP. 